Aly, H. and Strazicich, M.C. (2011). Global Financial Crisis and Africa: Is the Impact Permanent or Transitory? Time Series Evidence from North Africa. American Economic Review: Papers and Proceedings, 101(3): $577-581$ (May 2011). Published by the American Economic Association (ISSN: 0002-8282). DOI:10.1257/aer.101.3.577

\title{
Global Financial Crisis and Africa: Is the Impact Permanent or Transitory? Time Series Evidence from North Africa
}

Hassan Y. Aly and Mark C. Strazicich

\begin{abstract}
We utilize time series tests with structural breaks to test for an adverse impact on economic growth rates in North Africa associated with the recent US financial crisis and global recession. One or two breaks are identified for each country, except for Morocco where no break is found, while breaks coincide with the 2008 financial crisis in only two of the six countries (Libya and Mauritania). These findings suggest that, in general, shocks from the recent financial crisis have only temporary effects on economic growth in these countries. Impulse response functions with breaks confirm these results. We conclude by suggesting explanations for these findings.
\end{abstract}




\section{North Africa and the Recent Global Recession}

The North African (NA) countries are receiving increasing attention with the publication of the 2010 Human Development Report (UNDP, HDR 2010). In particular, three of these NA countries-Tunisia, Algeria, and Morocco-are listed in the report among the top ten economies showing the greatest improvement in human development, as measured by the Human Development Index (UNDP, HDI 2010), relative to their 1970 starting points. As can be seen in Table 1, the NA region was not only more resilient in the recent global economic crisis than the rest of the African continent, but performed better than nearly all other regions of the world (except for emerging Asia). Specifically, the recent financial crisis did not result in a recession in the NA region, as real gross domestic product (GDP) growth remained positive while declining by about 2 percentage points from 5.4 percent in 2008 to 3.8 percent in 2009.

A look at the individual countries provides a more detailed picture. For instance, Libya and Algeria, two oil exporting countries, saw their real GDP growth slow to 2.1 percent and 2.2 percent in 2009 from 3.8 percent and 2.4 percent in 2008 , respectively, due to a fall in international oil prices and lower production quotas imposed by the Organization of the Petroleum Exporting Countries (OPEC). 1 For Egypt, the balance of payments was in deficit for the first time in five years, due to declining trade account receipts, falling remittances from abroad, and receding foreign investment, in addition to stimulus packages adopted to mitigate the impact of the crisis. 2 In Morocco and Tunisia, the growth rate of real GDP declined to 5.0 percent and 3.1 percent in 2009 from the previous year's growth rates of 5.6 percent and 4.6 percent, respectively, essentially due to a decline in exports of manufactured products to the European region. Within the region, Mauritania is the only country to have a negative growth rate in 2009 . The crisis can also be seen as a blessing in disguise for the oil importing countries in the region, given that the price of oil and major food items plummeted, leading to lower inflation rates in these countries. 3 


\section{Methodology}

The primary question that we seek to address is whether the recent financial crisis originating in the United States, and the recession that followed, had a significant impact on the economies of Algeria, Egypt, Libya, Mauritania, Morocco, and Tunisia. To examine this, we utilize annual data from 1980 to 2015 (IMF 2010). This dataset is convenient, since the IMF provides forecasts through 2015 when current data are not available. Thus, while these results can be seen as preliminary, the use of this dataset allows us to test for a structural break during the recent financial crisis, which can be useful to policymakers and others interested in obtaining expedient information.

We focus our investigation on the annual rate of economic growth in each country as measured by the percentage change in real GDP. Since our dataset is in constant price national currency units, we additionally consider time series on national currency units per current international dollar to control for fluctuations in exchange rates (1980-2015, IMF 2010). Since the recent financial crisis is generally regarded to have originated in the United States, we include the annual growth rate of US real GDP in our investigation. Given that the European Union (EU) is a major trading partner with the NA countries, and a major world economic region, we also include the annual growth rate of the EU real GDP in our tests.

Table 1-Real GDP Growth Rates, 2007-2010

\begin{tabular}{lcccc}
\hline \hline Country or region & 2007 & 2008 & $2009(\mathrm{e})$ & $2010(\mathrm{p})$ \\
\hline Algeria & 3.0 & 2.4 & 2.2 & 3.9 \\
Egypt & 7.1 & 7.2 & 4.7 & 5.4 \\
Libya & 6.0 & 3.8 & 2.1 & 5.2 \\
Mauritania & 1.0 & 3.7 & -1.1 & 4.5 \\
Morocco & 2.7 & 5.6 & 5.0 & 4.3 \\
Tunisia & 6.3 & 4.6 & 3.1 & 4.0 \\
North Africa & - & 5.4 & 3.8 & 4.8 \\
Middle East and North Africa & 5.6 & 5.1 & 2.4 & 4.5 \\
Sub-Sahara Africa (SSA) & 6.9 & 5.7 & 1.6 & 4.3 \\
Central and Eastern Europe & 5.5 & 3.0 & -3.7 & 2.8 \\
Developing Asia & 10.6 & 7.9 & 6.6 & 8.7 \\
\hline
\end{tabular}

Source: African Development Bank (ADB), March 2010, estimation, and World Economic Outlook, International Monetary Fund (IMF), April 2010, estimation. 
Structural breaks are highlighted in our investigation for two reasons. First, we want to identify if economic growth rates in the NA region are stationary. If growth rates are stationary, then shocks will have temporary effects. In contrast, if growth rates are nonstationary, then shocks will have permanent effects with no tendency to return to a stable mean or trend. As is well known, ignoring an existing structural break in unit root tests will lead to a bias against rejecting a false unit root. Second, we want to identify if significant breaks in economic growth are present at the time of the recent financial crisis.

To test for a unit root and allow for structural breaks, we utilize the endogenous one- and two-break Lagrange multiplier (LM) unit root tests of Lee and Strazicich $(2003,2004)$. These tests identify one or two breaks in the level and trend of the series while testing the null of a unit root, and are valid whether breaks occur under the null or alternative hypothesis. We begin by using the two-break test and examine the $t$-statistics on the identified breaks. If only one break is significant at the 10 percent level, then testing is repeated using the one-break test. If no break is significant, then conventional Augmented Dickey-

Fuller (ADF) unit root tests will be utilized.

After testing for unit roots and breaks, we then estimate vector autoregression (VAR) models for each country, while controlling for the breaks identified with the unit root tests. Following this, we estimate impulse response functions to look for further evidence of an impact on the NA economies from the US financial crisis and recession. Given that we include the growth rate of the EU in our VAR models, we additionally examine the interplay between the NA, US, and EU economies. As noted, economic growth in the EU may have a greater impact on the NA economies than the US growth rate, due to the greater linkages in trade and remittances (Muhlberger and Semmelmann 2010). The rate of currency depreciation is also included in the VAR models to control for fluctuations in exchange rates. 


\section{Results}

The LM unit root test results are displayed in Table 2. The results indicate that in each country, except the US, the null of a unit root in the rate of economic growth is rejected at the usual significance levels. One or two breaks are identified for each country, except for Morocco.

Examination of the breaks provides some interesting results. Nearly every break is associated with a US recession (1990-1991, 2001, and 2008). However, in only two of the six NA countries (Libya and Mauritania) is there a break in growth in the time period of the recent financial crisis (2008). Note that while only one break is identified for Egypt, the identified break year of 1994 does not correspond with any of the recent US recessions. As might be expected, structural breaks in economic growth at the time of the recent economic crisis are identified in both the US and the EU in 2008. The other identified breaks, 1990 in the US and 1992 in the EU, correspond with recessions that occurred in the US in 1991 and the EU in 1992-1993, respectively.

Given that no break was identified for Morocco, we report results using the conventional (nobreak) ADF unit root test in this case. Given that each of the NA growth rates is stationary around one or two breaks, except for Morocco which has no break, we conclude that shocks to growth have temporary effects, with the exception of one or two permanent trend breaks that are, in nearly every case, associated with earlier US and EU recessions.

To further our investigation, we next utilize the identified breaks to estimate VAR models and impulse response functions for each country. Given the possibility that some growth rates may be stationary even if breaks are omitted from the unit root tests, we also performed conventional ADF tests on each series prior to estimating the VAR models. In each country except Algeria and Tunisia, we can reject a unit root at the usual significance levels. Note that the 1990 break identified for Algeria and Tunisia is already included in the VAR model, since this is one of the breaks for the US. Therefore, to conserve degrees of freedom, we focus our VAR investigation on the 1990 and 2008 breaks from 
the US real GDP growth rate and include an additional break of 2002 only in the VAR model for Algeria. Given our limited time span, we omit Libya from our VAR investigation, since including two additional breaks in 1999 and 2006 would be necessary to ensure stationarity in Libya's currency depreciation, while neither of these breaks is associated with the US breaks of 1990 and 2008. The number of lags in each VAR model was determined by minimizing the Schwarz Information Criterion (SIC). All VAR models include a trend term, which also led to the lowest SIC, or nearly so, in each case.

Table 2 - LM Unit Root Test Results, Annual Percentage Change in Real GDP,

1980-2015

\begin{tabular}{lcccc}
\hline \hline Country & $k$ & Breaks & Test statistic & $\lambda$ \\
\hline Algeria & 4 & 1990,2002 & $-5.3227^{*}$ & $\lambda=(0.4,0.6)$ \\
Egypt & 8 & 1994 & $-5.1966^{* * *}$ & $\lambda=(0.4)$ \\
Libya & 7 & 2002,2008 & $-9.6185^{* * *}$ & $\lambda=(0.6,0.8)$ \\
Mauritania & 8 & 1993,2008 & $-8.0121^{* * *}$ & $\lambda=(0.4,0.8)$ \\
Morocco & 0 & - & $-12.2427 * * *$ & - \\
Tunisia & 6 & 1990 & $-4.9036^{* * *}$ & $\lambda=(0.4)$ \\
United States & 8 & 1990,2008 & -4.9728 & $\lambda=(0.4,0.8)$ \\
European Union & 7 & 1992,2008 & $-6.774^{* * *}$ & $\lambda=(0.4,0.8)$ \\
\hline
\end{tabular}

Notes: The number of lagged first-differenced terms included to correct for serial correlation is represented by $k$; $k$ was determined beginning with a maximum of eight lagged terms and dropping the maximum lagged term until the remaining maximum lagged term was significant at the 10 percent level. The unit root test critical values depend on the location of the breaks $\lambda=\left(T_{B 1} / T, T_{B 2} / T\right)$ and are symmetric around $\lambda$ and $(1-\lambda)$. Critical values come from Lee and Strazicich $(2003,2004)$.

$* * *$ Significant at the 1 percent level.

** Significant at the 5 percent level.

*Significant at the 10 percent level.

While some impact of shocks from the US or EU real GDP growth rates on NA growth rates is apparent from the impulse response functions, none is significantly different from zero. The only notable exception is for the impact on EU real GDP growth from a one-standard-deviation shock to US real GDP growth. In nearly every case, a one-standard-deviation (positive) shock to the US real GDP growth rate is associated with a 1 percent increase in the growth rate of the EU that declines to zero in approximately two years. We find no significant evidence that shocks to the EU real GDP growth rate affect the US real GDP growth rate. 4 


\section{Conclusion}

The most significant finding of this study is the overall confirmation of the resilience of the NA economies in the face of the global financial and economic crisis that erupted in the US in 2007-2008. While the NA region as a whole weathered the storm better than most, there are some notable differences at the country level. First, it appears that Morocco is the only NA country that experienced no significant impact from the recent financial crisis and global recession (no identified structural breaks). The case of Morocco is interesting since its situation is similar in many respects to that of Tunisia, which experienced a larger transitory effect. A major bumper crop in the second half of 2009 (30.7 percent growth) helped Morocco to mitigate the recent financial crisis and avoid a significant impact on economic growth. Moreover, Morocco experienced an acceleration of 6 percent growth in mining, manufacturing, and construction during this time period.

Tunisia, Egypt, and Algeria experienced some transitory effect in economic growth during the financial crisis, but no permanent break. In particular, these three countries adopted expansionary fiscal policies to counter the adverse effects of the recent financial crisis. Egypt's government, for example, enacted two major stimulus packages and lowered interest rates to boost economic activity, while targeted projects cushioned the effects of the crisis on the most exposed sectors, such as manufacturing, tourism, and foreign trade (African Development Bank 2010).

The two remaining and very diverse countries of Mauritania and Libya each witnessed significant breaks in 2008. While the impact on economic growth following the break in Mauritania is predominantly negative, the corresponding break in Libya is rather positive. Mauritania is a somewhat special case in North Africa. With its less developed economy and relatively small population, Mauritania can be seen as an outlier among the NA countries. In particular, the recent financial crisis was not expected to have an impact on Mauritania's economy due to its mostly isolated financial system in the region. 
Nevertheless, Mauritania was the only economy in the region to experience negative growth in 2009. The major culprit, however, was likely not the global recession or financial turbulence per se, but the collapse of domestic security and economic calamities that followed the 2008 coup d'état.

Turning to Libya, one of Africa's wealthiest nations - with the continent's largest proven oil reserves and the third largest African oil producer behind Angola and Nigeria-the country was only moderately affected by the global economic and financial crisis early on due to lower oil prices. Soon after, however, the lower commodity prices eased inflation to approximately 2.5 percent for the first nine months of 2009 , as compared to 10.4 percent year on year. Furthermore, and most important, the recent financial crisis coincided with the complete lifting of international economic sanctions and inclusion of Libya in the community of nations. Libya did not waste time in using the lifting of sanctions to its advantage. Most notably, the recent financial crisis presented Libya with an opportunity to acquire some major foreign assets. In late 2008, for example, Libya invested in the ailing Unicredit, Italy's second largest bank. While rich country investors have been retrenching during the slowdown, Libya is emerging as a key player by picking up discounted European assets. Most important, however, starting in 2007, Libya embarked on a major program of diversification and privatization, inducing competition in the private sector, in addition to undertaking a major investment in domestic infrastructure and tourism.

In sum, these findings highlight the resilience of the NA economies to the recent financial crisis and global recession. An immediate research question points toward the impact of the recent eurozone crisis and debt problems coupled with a recent rise in food prices. Whether this new round of economic tribulations will affect the NA region might be the next logical step to extend our current line of research. 


\section{NOTES}

1 African Development Bank platform data, 2009.

2 African Economic Outlook (2010, Egypt, country notes).

3 African Economic Outlook (2010, various country notes).

4 The ADF test results and the estimated VAR models and impulse response functions were omitted to conserve space, but are available from the authors upon request.

\section{REFERENCES}

African Development Bank. 2010. African Economic Outlook 2010. http://www. africaneconomicoutlook. org/en/countries/north-africa/ egypt/.

International Monetary Fund. 2010. http://www. imf.org/external/pubs/ft/weodata/index.aspx.

Lee, Junsoo, and Mark C. Strazicich. 2003. "Minimum Lagrange Multiplier Unit Root Test with

Two Structural Breaks." Review of Economics and Statistics, 85(4): 1082-89.

Lee, Junsoo, and Mark C. Strazicich. 2004. "Minimum LM Unit Root Test with One Structural Break." Unpublished.

Muhlberger, M., and M. Semmelmann. 2010.

"North Africa-Mediterranean Neighbours on the Rise." Deutsche Bank Research. http://www. dbresearch.com/PROD/DBR_INTERNET EN-PROD/PROD00000000000258295.pdf.

United Nations Development Programme. 2010. Human Development Report 2010: The Real Wealth of Nations: Pathways to Human Development. New York: Palgrave Macmillan. 